\title{
Mapeamento da Formação Pedagógica de docentes universitários nas Universidades Públicas Portuguesas
}

\author{
Amanda Rezende Costa Xavier \& Carlinda Leite
}

Resumo:

As transformações recentes no ensino superior, associadas ao Processo de Bolonha, impuseram uma reforma curricular que, entre outros aspetos, apontam para a reconfiguração das práticas pedagógicas docentes, veiculando um discurso de rutura com o paradigma baseado na transmissão de conhecimentos, para passar a privilegiar a ação dos estudantes na construção das suas aprendizagens. Esta orientação fundamenta o estudo realizado e que responde à pergunta: que atenção é dada pelas universidades públicas portuguesas à criação de espaços de construção de saberes da docência, em que os professores desenvolvam competências pedagógicas em linha com os desafios curriculares do Processo de Bolonha? O estudo recolheu dados nas páginas eletrónicas de 13 das 14 universidades públicas portuguesas relativos aos planos estratégicos e de ação, aos setores responsáveis pela formação pedagógica docente, e às agendas de formação. A análise de conteúdo desses dados permitiu constatar que, embora existam estruturas institucionais que se ocupam desta dimensão pedagógica nas universidades, o modo como são alocadas na organização e nas competências que Ihes cabem evidenciam um nível distinto de compromisso das universidades com a formação dos seus docentes. Há as que demonstram estar em fase de implementação de projetos que poderão resultar em espaços formativos institucionais, mas também as que ainda não se ocupam da questão da formação pedagógica e apoio à docência.

Palavras-chave:

pedagogia universitária; assessoria pedagógica universitária; formação pedagógica docente; processo de Bolonha. 


\title{
Mapping of Pedagogical Training of University Professors in Portuguese Public Universities
}

\begin{abstract}
The recent transformations in higher education, associated with the Bologna Process, imposed a curricular reform that, among other aspects, points to a reconfiguration of teaching pedagogical practices. The political discourse conveyed affirms a rupture with the paradigm supported in the transmission of knowledge, to privilege the action of the students in the construction of their own learning. This scenario, which emerges from the Bologna Process, is the foundation for a study that answers the question: what attention is given by the Portuguese public universities, to the creation of spaces for the construction of teaching knowledge where teachers can develop skills to respond to the curricular challenges of the Bologna Process? The study collected data through the institution's electronic pages, related to strategic and action plans, as well as the sectors responsible for teacher education, and their training agendas, from13 of the 14 Portuguese public universities. The content analysis of these data showed that, although with institutional structures that deal with this pedagogical dimension, the way they are allocated in the universities organization and competences, show a distinct level of commitment of their teacher's education. There are those that demonstrate being in the phase of the implementation of projects that may result in institutional formative spaces, but also those that do not yet deal with the issue of pedagogical training and teaching support.
\end{abstract}

Keywords: university pedagogy; university pedagogical advisory; teacher training; Bologna process.

\section{Cartographie de la formation pédagogique des professeurs d'université dans les universités publiques portugaises}

Résumé: Les changements récents dans l'enseignement supérieur, associés au Processus de Bologne, ont imposé une réforme des programmes qui, entre autres aspects, suggère une reconfiguration des pratiques pédagogiques de l'enseignement, traduisant un discours de rupture avec le paradigme fondé sur la transmission des connaissances, de façon à privilégier l'action des étudiants dans la construction de leur apprentissage. Cette approche sus-tend l'étude réalisée pour répondre à la question: quelle est l'attention donnée par les universités publiques portugaises à la création d'espaces pour la construction de connaissances pédagogiques dans lesquelles les enseignants développent des compétences pédagogiques en ligne avec les défis curriculaires du Processus de Bologne ? L'étude a rassemblé des données sur les sites internet de 13 des 14 universités publiques portugaises concernant les plans stratégiques et d'action, les secteurs responsables de la formation pédagogique des enseignants et les agendas de formation. L'analyse de contenu de ces données a montré que, bien qu'il existe des structures institutionnelles qui traitent de cette dimension pédagogique dans les universités, la manière dont elles sont réparties dans leur organisation et leurs compétences montre un niveau distinct d'engagement des universités dans la formation de leurs enseignants. II y en a ceux qui démontrent être dans la phase de mise en œuvre des projets qui peuvent aboutir à des espaces de formation institutionnels, mais il y en a aussi ceux qui ne sont pas encore concernés par la question de la formation pédagogique et du soutien à l'enseignement.

Mots-clés: pédagogie universitaire; conseil pédagogique universitaire; formation pédagogique des enseignants; processus de Bologne.

\section{Mapeo de la formación pedagógica del profesorado en las universidades públicas portuguesas}

Resumen: Las transformaciones recientes en la educación superior, asociadas al Proceso de Bolonia, impusieron una reforma curricular que, entre otros aspectos, apunta a la reconfiguración de las prácticas pedagógicas docentes, vehiculando un discurso de ruptura con el paradigma apoyado en la transmisión de conocimientos, para privilegiar la acción de los estudiantes en la construcción de sus aprendizajes. Esta orientación subyace el estudio realizado y responde a la pregunta: ¿qué atención es dado por las universidades públicas portuguesas a la creación de espacios para la construcción de los saberes de la docencia, en que los maestros desarrollan competencias pedagógicas en línea con los desafíos curriculares del Proceso de Bolonia? El estudio recolectó datos en los sitios electrónicos de 13 de las 14 universidades públicas portuguesas en relación a los planes estratégicos y de acción, a sectores responsables de la formación pedagógica docente, y agendas de formación. El análisis de contenido de estos datos mostró que, aunque existen estructuras institucionales que se ocupan de la dimensión pedagógica en las universidades, el modo en que se asignan en su organización y con las competencias que les corresponden, evidencian un nivel distinto de compromiso de las universidades con la formación de sus docentes. Hay quienes demuestran estar en la fase de implementación de proyectos que pueden dar lugar a espacios formativos institucionales, pero también aquellos que aún no están preocupados por el tema de la capacitación pedagógica y el apoyo a la enseñanza.

Palabras clave: pedagogía universitaria; asesoría pedagógica universitaria; formación pedagógica docente; proceso de Bolonia. 


\section{Introdução}

O estudo que este artigo apresenta tem por referência o contexto curricular introduzido pelo Processo de Bolonha e como pressuposto a ideia que ele tem provocado, no ensino superior, efeitos de natureza pedagógica que trazem exigências aos docentes universitários. Essas transformações, provocadas pelo discurso do Processo de Bolonha, colocam o insucesso académico dos estudantes em condição reprovável, seja pela lógica política, porque frustra os investimentos económicos efetuados, seja pela ótica social, porque frustra as expectativas e o propósito pedagógico da formação educacional universitária.

No quadro destas ideias tem sido evidenciada a iminência de se concretizar a docência universitária alicerçada no paradigma da aprendizagem, isto é, num modelo que exige a promoção da autonomia do estudante, em rutura com o modelo tradicional de ensino (Leite, 2010). Esta situação "confrontou muitos dos professores com a dificuldade acrescida de recorrerem a processos pedagógico-didáticos em que os estudantes tenham um papel ativo na aprendizagem" (Leite \& Ramos, 2015, p. 37).

Como tem sido reconhecido, esta nova orientação implica que os professores universitários dominem saberes pedagógicos que os capacitem para lidar com as situações que se apresentam à docência. Entretanto, estudos do campo da Pedagogia Universitária (Cunha 2010a, 2010b; Leite, 2010; Leite \& Ramos, 2014) têm mostrado que esses saberes nem sempre estão construídos e dominados pelos docentes deste nível de ensino ou que eles não ocupam lugar central no cotidiano académico. Frente a este reconhecimento, entendemos que a adequação ao paradigma para que aponta o Processo de Bolonha reforça a necessidade de as instituições de ensino superior se comprometerem com a formação pedagógica dos seus docentes, criando-lhes condições para enfrentarem os desafios que o exercício cotidiano da docência coloca. Neste entendimento, consideramos importante a existência de setores institucionais que se ocupem da formação pedagógica, entendendo-a como uma componente do desenvolvimento profissional docente.

É tendo por referência esta problemática que foi realizado um estudo na intenção de responder à pergunta: que atenção é dada pelas universidades públicas portuguesas à criação de espaços de construção de saberes da docência, em que os professores desenvolvam competências pedagógicas em linha com os desafios curriculares do Processo de Bolonha?

\section{Assessoria Pedagógica Universitária: delimitação do quadro teórico}

O compromisso institucional com a formação pedagógica dos docentes universitários, em alguns países (como Brasil, Argentina, Uruguai, por exemplo), implica a existência de Assessorias Pedagógicas Universitárias, que tenham entre as suas responsabilidades 
promover espaços de construção de saberes da docência, que atendam às demandas dos professores universitários. Integrando o campo de conhecimentos que compõem a Pedagogia Universitária, a Assessoria Pedagógica tem como objetos de estudo e de trabalho questões que envolvem o ensino, a aprendizagem e a avaliação na Universidade (Lucarelli, 2007), buscando tornar uma prática a reflexão pedagógica para o exercício da docência universitária (Xavier, 2014). A função de Assessoria, em alguns países, "é reconhecida como uma profissão de ajuda em um meio onde as práticas de intervenção se orientam para obter mudanças que afetam a instituição educativa como um todo e a aula em particular" (Lucarelli, 2008, p. 4). Se comparada à figura do amigo crítico a que se refere Leite (2002), a Assessoria Pedagógica exerce seu papel ao ser reconhecida por seus conhecimentos e competências relativos ao contexto educativo, num processo de confiança construído num clima de partilhas e aprendizagens.

Nas instituições universitárias, tal setor deve desenvolver atividades que favorecem o desenvolvimento profissional docente, numa lógica de construção de comunidades de aprendizagem, de forma que "a rutura com o individualismo constitua resposta aos desafios da atividade docente" (Gomes \& Tavares, 2017, p. 28). Como se depreende, percebemos as Assessorias Pedagógicas Universitárias como dispositivos de apoio, cujas práticas de intervenção, de animação e de orientação se entrelaçam às práticas pedagógicas docentes, não as deixando isoladas (Lucarelli, 2007). A Assessoria Pedagógica Universitária representa, portanto, o lugar da Pedagogia Universitária e, por isso, precisa de ser um espaço legitimado (Broilo, 2015; Xavier, Toti \& Azevedo, 2017) e comprometido institucionalmente (Cunha, 2014).

Como se infere, compreender esses setores institucionais é compreender o modo como a instituição, ao se ocupar da formação pedagógica, valoriza tal questão e cria condições para que estes enfrentem os desafios impostos à docência, tendo em conta os movimentos de transformação por que passa o ensino superior e que exigem "a recriação da universidade pelos valores da tradição inovadora” (Almeida Filho, 2016, p. 28).

\section{Procedimentos metodológicos}

Tendo por ponto de partida a questão de investigação atrás enunciada, o estudo recolheu dados de 13 das 14 Universidades Públicas existentes em Portugal, e mapeou a organização da formação pedagógica docente pelos setores institucionais responsáveis que assumem responsabilidades que consideramos da competência das Assessorias Pedagógicas Universitárias.

Na constituição deste corpus, não foi incluída a Universidade Aberta (UAb) por se tratar da única instituição de ensino superior público a distância em Portugal, ou seja, toda a oferta pedagógica é lecionada em regime de elearning ${ }^{1}$, fator que a distancia do foco deste estudo. 
O estudo, que produziu um mapeamento da atenção que é dada pelas universidades públicas portuguesas à criação de espaços de construção de saberes da docência, foi realizado a partir de dois procedimentos metodológicos: a pesquisa em portais eletrónicos institucionais e a pesquisa em documentos estratégicos institucionais. Para a pesquisa foram usados os descritores 'formação', 'formação pedagógica', 'formação de docentes', 'formação de professores'. O período de análise dos portais eletrónicos institucionais ocorreu entre os dias 01 de outubro e 30 de novembro de 2017. Os documentos recolhidos nos portais eletrónicos das instituições, e a partir dos quais foi feita a análise de conteúdo (Bardin, 2011), foram: os Planos de Desenvolvimento Institucional (PDI), documento que traça os objetivos e metas da instituição. Esse documento equivale ao Plano Estratégico ou ao Plano Pedagógico, dependendo das decisões organizacionais de cada universidade e, em nosso entendimento, referenda as ações institucionais de formação pedagógica, percebendo-a como fundamental para o sucesso e a qualidade da prática docente, principalmente nos contextos curriculares que denotam inovação.

O segundo procedimento seguido na pesquisa pretendeu identificar os setores institucionais responsáveis pela formação pedagógica dos docentes, indistintamente da linha adotada por cada universidade. O requisito estabelecido limitou os setores à dimensão institucional, ou seja, foram reconhecidos os setores associados à administração geral da universidade, e que, decorrente dessa posição organizacional, trata a formação pedagógica como um serviço que deva ser planeado, pensado e oferecido indistintamente para todos os docentes universitários. Neste procedimento foram também seguidos critérios de exclusão da amostra que se afastavam do objeto de estudo. Setores locais que se ocupam da formação dos docentes, vinculados a determinadas Faculdades ou Departamentos, foram excluídos. Considerou-se que este critério de exclusão faz sentido porque, mesmo tendo em conta a manifestação crescente de um processo local de formação pedagógica, eles ocupam-se das suas próprias demandas formativas, que serão também específicas, ainda que a participação seja aberta a docentes de outras unidades. Nesta mesma lógica foram excluídos projetos que, embora representem uma atividade de formação pedagógica, são de responsabilidade de determinadas Faculdades ou Institutos. O critério de exclusão atingiu também os Centros de pesquisa e investigação, porque, ainda que ofereçam formação à comunidade académica, fazem-no como consequência dos seus projetos, isto é, a sua identidade não se alicerça na formação pedagógica docente como responsabilidade institucional. Por fim, também foram igualmente excluídos os órgãos ou centros que se ocupam da formação contínua destinada à comunidade (long life learning), porque sua oferta formativa é paga pelos participantes. Deste modo, ainda que estes órgãos ofereçam muitas atividades de formação, o plano não é preparado especificamente para os docentes universitários. No entanto, quando um mesmo órgão se responsabiliza quer 
pela oferta de atividades que visam a formação da comunidade ao longo da vida, quer da formação pedagógica dos docentes da própria instituição, foram distinguidas essas ações, para que o objeto de estudos não fosse comprometido.

Foi seguindo este percurso que construímos o mapeamento que dá uma visão da oferta de formação pedagógica institucional aos docentes universitários que vivenciam as realidades impostas pelas transformações decorridas do Processo de Bolonha, em Portugal.

\section{A formação pedagógica docente: apresentação e discussão dos dados}

O mapeamento da formação pedagógica dos docentes disponível nas 13 universidades públicas portuguesas está sistematizado na Tabela 1 e permite conhecer: a quem compete a responsabilidade dessa formação; a existência, ou não, de um Plano de Desenvolvimento Institucional (PDI); o tipo de modalidade de formação que é oferecida; a existência de incentivos à formação; e a existência, ou não, de um plano de formação disponibilizado nos sites eletrónicos.

Tabela 1 - Formação Pedagógica nas universidades públicas de Portugal

\begin{tabular}{|c|c|c|c|c|c|}
\hline \multirow[b]{2}{*}{ 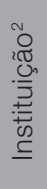 } & \multicolumn{5}{|c|}{ Formação Pedagógica Docente } \\
\hline & Responsabilidade & $\begin{array}{l}\text { Previsão no } \\
\text { PDI } \\
\text { (documento } \\
\text { similar) }\end{array}$ & $\begin{array}{c}\text { Modalidade } \\
\text { Formativa }\end{array}$ & $\begin{array}{c}\text { Incentivos extra à } \\
\text { formação }\end{array}$ & $\begin{array}{c}\text { Plano de } \\
\text { Formação } \\
\text { (disponibilizado) }\end{array}$ \\
\hline 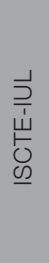 & $\begin{array}{c}\text { Pró-Reitoria de } \\
\text { Inovação Curricular e } \\
\text { Pedagógica } \\
\text { - Grupo de Trabalho } \\
\text { do Sucesso } \\
\text { Acadêmico } \\
\text { - Gabinete de } \\
\text { Acesso e Sucesso no } \\
\text { Ensino Superior }\end{array}$ & Sim & $\begin{array}{c}\text { Semana } \\
\text { Pedagógica }\end{array}$ & $\begin{array}{l}\text { Material de estudos } \\
\text { disponibilizados } \\
\text { Prémio Pedagógico }\end{array}$ & Não \\
\hline$\stackrel{\bar{m}}{\supset}$ & $\begin{array}{l}\text { Equipe Reitoral } \\
\text { - Gabinete da } \\
\text { Qualidade }\end{array}$ & Sim & - & $\begin{array}{l}\text { Prémio Mérito } \\
\text { Pedagógico }\end{array}$ & Não \\
\hline$\sum_{J}^{\pi}$ & $\begin{array}{l}\text { Equipe Reitoral } \\
\text { - Centro de } \\
\text { Desenvolvimento } \\
\text { Acadêmico }\end{array}$ & Sim & $\begin{array}{l}\text { Atividades de } \\
\text { curta duração }\end{array}$ & Não & Sim \\
\hline 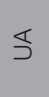 & $\begin{array}{l}\text { Pró-Reitoria de } \\
\text { Acreditação dos } \\
\text { Ciclos de Estudos }\end{array}$ & Não & $\begin{array}{c}\text { Evento Teaching } \\
\text { Day }\end{array}$ & Não & Sim \\
\hline$\stackrel{0}{\supset}$ & $\begin{array}{c}\text { Vice-Reitoria para } \\
\text { assuntos acadêmicos, } \\
\text { ações sociais, } \\
\text { planeamento e } \\
\text { qualidade }\end{array}$ & Não & Projeto Ped@es & Não & Não \\
\hline
\end{tabular}




\begin{tabular}{|c|c|c|c|c|c|}
\hline 岗 & $\begin{array}{c}\text { Gabinete de } \\
\text { Planeamento e } \\
\text { Garantia da Qualidade } \\
\text { - Centro de } \\
\text { Tecnologias } \\
\text { Educativas }\end{array}$ & Sim & $\begin{array}{l}\text { Formação } \\
\text { e-docentes }\end{array}$ & Não & Não \\
\hline$\supset$ & $\begin{array}{c}\text { Reitoria } \\
\text { - Departamento } \\
\text { Acadêmico } \\
\text { - Núcleo de } \\
\text { Formação ao Longo } \\
\text { da Vida }\end{array}$ & $\operatorname{Sim}$ & $\begin{array}{c}\text { Programa } \\
\text { Formação } \\
\text { Pedagógica para } \\
\text { docentes }\end{array}$ & $\begin{array}{c}\text { Projeto Observar e } \\
\text { Aprender }\end{array}$ & Sim \\
\hline 是 & $\begin{array}{l}\text { Vice-Reitoria para a } \\
\text { área do ensino } \\
\text { - Gabinete de } \\
\text { Formação } \\
\text { - ELearning }\end{array}$ & Sim & $\begin{array}{l}\text { Programa } \\
\text { Formação } \\
\text { Pedagógico- } \\
\text { Didática para } \\
\text { docentes }\end{array}$ & Não & Sim \\
\hline$\frac{0}{5}$ & $\begin{array}{c}\text { Centro de Formação } \\
\text { e Atualização } \\
\text { Permanente }\end{array}$ & Sim & - & Não & Não \\
\hline 吕 & $\begin{array}{c}\text { Gabinete de Apoio ao } \\
\text { Ensino } \\
\text { - Núcleo de Formação } \\
\text { - Centro de Inovação } \\
\text { e Desenvolvimento } \\
\text { do Ensino e } \\
\text { Aprendizagem }\end{array}$ & Sim & Cursos regulares & $\begin{array}{l}\text { Prêmio Excelência } \\
\text { no ensino } \\
\text { Apoio a projetos } \\
\text { de ensino e } \\
\text { aprendizagem }\end{array}$ & Sim \\
\hline $\begin{array}{l}\stackrel{0}{t} \\
0 \\
\frac{0}{5}\end{array}$ & $\begin{array}{c}\text { Reitoria } \\
\text { - Pró-Reitoria para } \\
\text { Inovação Pedagógica } \\
\text { e Desporto } \\
\text { - Gabinete para } \\
\text { Inovação Pedagógica } \\
\text { - Unidade para a } \\
\text { Melhoria do Ensino e } \\
\text { Aprendizagem }\end{array}$ & Sim & $\begin{array}{l}\text { Cursos } \\
\text { regulares } \\
\text { Workshop anual } \\
\text { de inovação } \\
\text { e partilha } \\
\text { pedagógica }\end{array}$ & $\begin{array}{c}\text { Prêmio Excelência } \\
\text { Pedagógica } \\
\text { Projetos de } \\
\text { inovação } \\
\text { pedagógica } \\
\text { Unidade Curricular } \\
\text { InovPed } \\
\text { Projeto de Par em } \\
\text { Par } \\
\text { Materiais de estudo } \\
\text { e atualização de } \\
\text { conhecimentos }\end{array}$ & Sim \\
\hline 迹 & $\begin{array}{c}\text { Unidade de Estudos } \\
\text { Virtuais }\end{array}$ & Sim & - & Não & Não \\
\hline$\vec{z}$ & $\begin{array}{l}\text { Pró-Reitoria para } \\
\text { a Coordenação da } \\
\text { Escola Doutoral } \\
\text { e do Gabinete de } \\
\text { Desenvolvimento } \\
\text { Profissional dos } \\
\text { Docentes } \\
\text { - Gabinete de } \\
\text { Desenvolvimento } \\
\text { Profissional dos } \\
\text { Docentes }\end{array}$ & Não & $\begin{array}{c}\text { Curso } \\
\text { Acompanhamento } \\
\text { Pedagógico }\end{array}$ & Cadernos Nova & Não \\
\hline
\end{tabular}

Fonte: Elaborado pelas autoras com os dados da pesquisa. 
O mapeamento realizado permite saber que a formação pedagógica institucional vem sendo assumida de diferentes modos pelas universidades públicas portuguesas, nomeadamente pelas responsabilidades atribuídas aos setores que se ocupam desta atividade e dos modos de trabalho que seguem. Permitiu também constatar a existência, no mínimo, de cinco perspectivas básicas de organização da atividade de formação pedagógica docente, ao nível institucional. Realçamos que essa percepção foi construída pela análise dos documentos institucionais públicos, e não pela análise de práticas realizadas no interior das universidades. Como se depreende, este destaque reflete alguma limitação nesta percepção, pois muitas atividades podem estar a acontecer, no sentido da oferta de formação pedagógica aos docentes, mas que nos escapam em razão do percurso metodológico seguido. Cientes desta limitação, destacamos a colaboração dos informantes privilegiados aos quais recorremos, em algumas das instituições a que o estudo se refere, quando não encontrámos as informações pretendidas nos portais eletrónicos ou documentos institucionais. Por meio do acesso a esses informantes privilegiados, buscámos diminuir os riscos contidos nas análises realizadas a partir das poucas informações disponibilizadas publicamente.

Um outro dado relevante que decorre do percurso metodológico seguido, e que não podemos desconsiderar, é a dificuldade na obtenção de dados institucionais que devem ser e estar publicitados a toda a comunidade, principalmente quando se trata de instituições públicas. O que o estudo revelou foi uma grande dificuldade de obtenção das informações necessárias ao mapeamento da formação pedagógica. Muitas páginas institucionais não permitem fácil ou intuitivo acesso às informações, fazendo com que os dados procurados se tornem obscuros, incompletos ou inconsistentes. Esta condição permite-nos questionar se a dificuldade no acesso à informação desta natureza não revela, por si só, a desvalorização institucional da formação pedagógica, ainda que ela esteja prevista como objetivo estratégico nos documentos institucionais. Até que ponto a não cultura institucional da formação pedagógica, que conduz a um esvaziamento de participação dos docentes nas ações de formação, não é reforçada, cotidianamente, por pequenos movimentos institucionais, sejam eles relacionados com a não evidenciação dos setores que se ocupam da formação, quer sejam relacionados com a publicitação insuficiente das informações relativas a essa natureza de ações. Em contramão com esta situação, o que entendemos pertinente é que, a partir dos recursos de acesso à informação, como os portais eletrónicos das universidades públicas, os documentos, dados e atividades institucionais devem permitir que os interessados conheçam e compreendam as instituições e as suas realidades e cotidianos. Consideramos que a vida institucional deve ser refletida nos documentos, bem como nos recursos de acesso à informação, demonstrando eles mais do que informações técnicas, operacionais e regulatórias. 
Em linha com esta última ideia, procedemos à análise que está sintetizada no gráfico 1 e que dá conta de algumas características da formação pedagógica docente assumida pelas universidades públicas portuguesas mapeadas.

Gráfico 1 - Perspetivas de organização institucional da formação pedagógica nas Universidades Públicas de Portugal

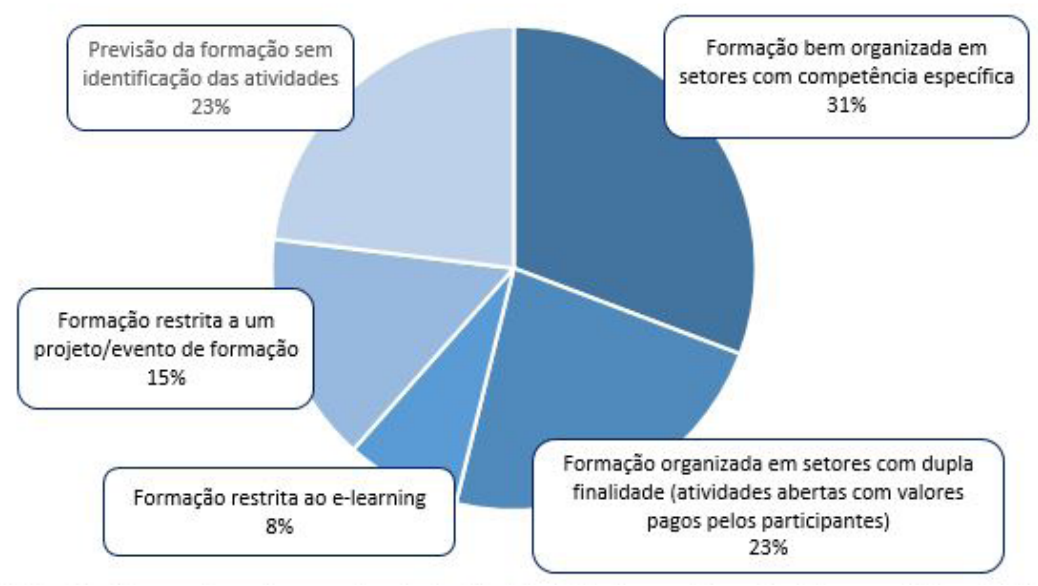

Fonte: Elaborado pelas autoras com os dados da pesquisa

$\mathrm{Na}$ primeira perspetiva, relativa a quatro das universidades (31\%), encontramos estruturas bem organizadas e definidas, que têm claro o objetivo institucional relativo à formação pedagógica dos docentes. Nestes casos, o PDI compromete-se com a questão da formação, valorizando-a a níveis institucionais, e os setores são identificados na estrutura organizacional, bem como as suas competências e responsabilidades relativas às ações de formação pedagógica, que são explicitadas e disponibilizadas nas páginas virtuais. Essa perspetiva de organização da formação pedagógica remete-nos para o entendimento de que os desafios impostos pelos pilares do Processo de Bolonha são percebidos institucionalmente como verdadeiros desafios à prática pedagógica docente, havendo a consequente perceção de que a valorização institucional dos professores passa pela responsabilidade conjunta para com o processo formativo, que os habilita a enfrentarem as realidades com que convivem nos processos de ensinar e de desencadear aprendizagem nos estudantes universitários.

Uma segunda perspetiva verificada em duas das universidades, mas cujas ações somente foram possíveis de serem identificadas em uma delas (por isso consideramos apenas $8 \%$ ), veicula a formação pedagógica à ideia única de utilização de tecnologias 
da informação e comunicação, o que orienta o objetivo da formação para questões do uso das tecnologias, depositando no setor de e-learning a única modalidade de formação. Nesse sentido, ainda que haja reconhecimento, nos documentos estratégicos, de que a formação pedagógica dos docentes é essencial para a garantia da qualidade do processo de ensinar e do processo de aprender, corre-se o risco de que a proposta formativa seja reducionista, impedindo que a discussão e reflexão da docência universitária na sua complexidade seja atingida. Este é um fator que merece atenção porque decorre do Processo de Bolonha um discurso que pode induzir o uso das tecnologias, na direção ao e-learning, como modo único de inovação pedagógica, o que contraria a caracterização desta inovação.

Na terceira perspetiva, identificada em 23\% das universidades, verificamos que os setores responsáveis pela formação pedagógica da instituição também se ocupam, paralelamente, à oferta de formação à comunidade, do atendimento às exigências da long life learning, pilar do Processo de Bolonha. Logo, esses setores organizam-se para atenderem a distintos objetivos institucionais, que não somente a formação interna dos professores da universidade. Assim, a formação existe, mas não unicamente no sentido de responsabilidade institucional que se compromete internamente com a formação dos seus professores, valorizando os processos de desenvolvimento profissional. Dentro desta perspectiva encontramos, em uma universidade, um modo de organização em que a formação pedagógica interna oferecida é cobrada financeiramente, em moldes idênticos ao que se passa com a oferta formativa para a comunidade externa à instituição. Essa perspetiva conduz-nos à ideia de que os pilares e desafios delineados com o Processo de Bolonha não são percebidos na sua dimensão pedagógica, se não, antes, percebidos numa lógica mercantilista, que transforma o ensino numa engrenagem económica. Neste cenário, o assessoramento pedagógico universitário não será mesmo importante, porque a atenção estará nos efeitos mercantis que os processos de formação podem desencadear.

A quarta perspetiva, verificada em 15\% das universidades públicas portuguesas estudadas, é aquela em que a instituição não prevê a formação pedagógica dentro dos planos estratégicos; porém são identificadas ações organizadas em torno de projetos institucionais específicos, de caráter formativo. Essa oferta, ainda que tenha grande valor para a formação dos professores, deixa escapar a possibilidade da construção de um lugar da formação, fomentando a identidade deste lugar como recurso de apoio à docência, frente aos desafios atuais vivenciados na profissão.

Finalmente, na quinta perspetiva, que abrange $23 \%$ das universidades, não são delimitadas claramente as ações institucionais de formação pedagógica docente. De tal modo, ainda que haja a previsão da formação nos documentos estratégicos institucionais, e até mesmo seja apontado o setor que por ela se responsabiliza, o conjunto de serviços, estratégias ou atividades em torno da formação não é identificado. Aqui 
parece que a questão da formação é mero acessório nos documentos institucionais, e, portanto, setores de assessoramento também o são; parece partir-se do princípio de que os professores universitários já dominam os conhecimentos necessários para a prática pedagógica, independentemente dos contextos curriculares em que se insiram.

Uma análise final dos dados recolhidos permite-nos perceber que, na primeira perspectiva, à medida que os setores responsáveis pela promoção da formação pedagógica docente se organizam institucionalmente, ampliando o seu nível de atuação e legitimidade junto dos docentes, vão potencializando a construção de uma cultura de reflexão pedagógica e valorizando a construção destes espaços formativos (Cunha, 2010a; Xavier, 2014; Broilo, 2015). Essa valorização, por consequência, leva à construção coletiva de saberes que alicerçam a docência e justificam as práticas pedagógicas adotadas pelos docentes. Sustentamos esta afirmação na ideia de que não se perdem as intencionalidades da formação pedagógica, distintamente do que ocorre quando pontualmente são realizadas ações nesse sentido, por alguns professores que se interessam pela dimensão pedagógica da profissão, sem existir uma estrutura formal que os sustentem. Essas ações pontuais, voltadas para a formação dos docentes, embora podendo ser muito positivas, podem, face às múltiplas tarefas que assumem os professores e para as quais são requisitados, ser perdidas ou postas em segundo plano. Nessas condições, perde-se o caráter de permanência e continuidade das ações formativas, facto menos possível de ser verificado se houver a institucionalização dos espaços de formação pedagógica e de apoio à docência, porque há um investimento intencional da instituição, nessa direção. Acreditamos que os setores responsáveis pelos espaços formativos podem apoiar a transposição das fronteiras criadas entre as inovações curriculares e a necessidade da inovação pedagógica, fronteiras que impedem que as transformações propostas atinjam o nível da concretização, mantendo-as somente no papel, isto é, enquanto intenção não concretizada. Deste modo, as Assessorias Pedagógicas, ou os setores a elas aproximados, ao romperem fronteiras, efetivam o seu espaço, podendo vir a constituir-se como um lugar da formação (Cunha, 2010a).

$\mathrm{Na}$ linha dos argumentos até aqui tecidos, é evidente que as potencialidades dos espaços próprios de construção de saberes se afirmarão se, aliadas às ações das assessorias ou dos setores responsáveis pela formação, existirem conceções de formação e de docência que valorizem a aprendizagem socializada desta profissão, enquanto dispositivo de desenvolvimento profissional. Neste sentido, a Assessoria Pedagógica, ou os setores aproximados que se ocupam da formação pedagógica, não se resumem a um espaço prescritivo do fazer docente; pelo contrário, configuram-se como espaço de construção e reconstrução de significados, nos quais se constroem respostas a situações que o exercício da docência impõe. Neste sentido constituem 
ruturas com lógicas de formação pautadas pelo fornecimento de receitas de práticas pedagógicas docentes.

A análise das demais perspetivas apresentadas permite-nos também organizá-las em dois conjuntos: aquelas que demonstram um caminhar institucional em direção ao avanço nas questões relativas à formação pedagógica docente, pois estão em fase de implementação de projetos que poderão resultar em espaços formativos institucionais; e aquelas que, de determinado modo, ainda não se ocupam da questão da formação pedagógica e apoio à docência. Assim, no subconjunto em que não se verificam os setores ou as ações desenvolvidas institucionalmente, ou ainda nos casos em que a formação pedagógica dos docentes da instituição é paralela à formação destinada à comunidade em geral, interna ou externa à universidade, referente à long life learning, parece-nos que se assume o risco de determinar o assessoramento pedagógico, e o próprio espaço de formação pedagógica institucional, como um não-lugar (Augé, 1994). Dito de outro modo, a partir destas perspetivas, reforça-se o entendimento de que os espaços de formação são espaços sem capacidade de constituir uma identidade de lugar de apoio à docência. Nestas condições, as relações, se chegarem a ser estabelecidas, poderão ser reduzidas a meras formalidades técnico-administrativas, sem condições de efetiva interferência na solitária prática da docência universitária, assumida em nome de uma dada interpretação da autonomia docente (Cunha, 2010b). Essa possibilidade negativa configura-se porque entendemos que não sendo previstos os espaços institucionalmente se reduz a responsabilidade pela formação pedagógica a interesses locais dentro da universidade, de modo que não se atinge o corpo docente na sua gama de interesses e necessidades formativas. Nesse sentido, também ficam comprometidos a evolução e o aprofundamento dos trabalhos que direcionam a formação pedagógica, exatamente pelo facto de que, confinadas em ações individuais ou de pequenos grupos que já têm outras responsabilidades e funções, o compromisso com a formação pode ser secundarizado, não por descaso, mas por exigência das múltiplas tarefas e responsabilidades do trabalho docente.

Quando se mercadoriza a formação pedagógica dos próprios docentes, em detrimento de uma conceção de compromisso institucional, também se permite a compreensão de um não-lugar, porque se explicita reconhecimento de unilateralidade da responsabilidade pela formação. Quer isto dizer que se explicita que compete à individualidade dos professores a busca por formação pedagógica, e, se esta for entendida como necessária, deve-se pagar por ela um determinado preço. Deste modo, o espaço de formação não se constituirá em um lugar (Cunha, 2010a), no qual o professor se integra e se sente parte no acolhimento. Torna-se um não-lugar (Augé, 1994) porque torna-se um mercado, ou seja, um lugar de trânsito, apenas. Logo, esta questão representa um descompromisso institucional para com os desafios com que se deparam os docentes. Por isso, consideramos que tais situações alimentam a cultura 
institucional que não tem a reflexão pedagógica como uma prática, mesmo que tenha alguma validade para os processos de ensinar e de aprender configurados nos pilares pedagógicos exigidos na universidade atual.

\section{Considerações Finais}

Assumindo como fundamental o papel exercido pelas Assessorias Pedagógicas Universitárias, no sentido de promoverem espaços de formação que se ocupem da construção de saberes da docência, o estudo apresentado permitiu concluir que algumas das universidades públicas em Portugal têm ratificado esta posição, buscando a institucionalização de setores que se ocupam da formação pedagógica docente, ainda que utilizando diferentes modos para os definir e concretizar.

Contudo, a diversificação das competências e dos modelos adotados pode vir a impedir o estabelecimento de uma identidade específica desses setores. Em nossa opinião, a falta de identidade pode ter como consequência o desconhecimento das ações e dos objetivos institucionais que justificam a formação pedagógica docente no ensino superior. A não criação de um serviço específico que dialoga institucionalmente com os docentes e que cria uma cultura de formação pedagógica interfere na atenção e no reconhecimento que the deve ser dada por toda a comunidade académica. Ter identidade conduz à perceção de que os docentes têm um apoio formal para as questões em torno dos processos de ensinar e de aprender na universidade, e que podem recorrer a esse setor sempre que dele sentirem necessidade. Essa identidade com a formação pedagógica auxilia, inclusive, a nosso ver, a rutura com o isolamento da profissão docente, constituindo um espaço coletivo de apoio à construção de saberes docentes se se apoiar num clima de troca e partilha de intervenções no campo da prática pedagógica.

Importante é realçar que, ainda que a maior parte das instituições se responsabilize pela implementação de setores que se ocupam de atividades típicas das Assessorias Pedagógicas, e estejam num caminho de consolidação da formação pedagógica, outras há que não têm essa atenção. Esta constatação demonstra que ainda há desvalorização da reflexão pedagógica em espaços próprios para a formação docente, perpetuando a lógica da não discussão dos modos de trabalho da docência universitária. Este facto reforça a lógica de que a dimensão pedagógica é legítima apenas no ensino não superior, ficando o ensino universitário ausente nos efeitos de seus próprios discursos acerca da prática docente. Essa não preocupação permite também inferir que a consolidação desses setores se limita com a transitoriedade das estratégias de gestão.

Não podendo ignorar que a concretização das inovações curriculares decorrentes do Processo de Bolonha demanda dos docentes uma inovação das suas práticas, a 
existência de instituições que não valorizam a formação coloca em risco a oportunidade de proporcionar aos docentes um espaço de apoio à concretização dessa inovação pedagógica, configurada na rutura paradigmática de um processo focalizado no ensino ministrado pelo professor, para um processo focalizado no estudante, ativo na construção das suas aprendizagens. Olhando a situação em outra perspetiva, estas situações dão força à ideia de que se transformam as políticas, as expectativas, as orientações para os currículos, mas sem o devido efeito na prática. Por isso, visualizamos um trabalho ainda árduo a ser perseguido pelos responsáveis universitários, de modo que busquem a consolidação de espaços institucionais que configurem e concretizem projetos comprometidos de formação que, em diálogo com os docentes, contribuam para uma inovação pedagógica e para um apoio de práticas relacionadas com saberes próprios da profissão.

\section{Notas}

${ }^{1}$ Fonte: Universidade Aberta. Disponível em <http://portal.uab.pt/auab/>.

${ }^{2}$ Lista de Abreviaturas: ISCTE-IUL: Instituto Universitário de Lisboa; UBI: Universidade da Beira Interior; UMa: Universidade da Madeira; UA: Universidade do Aveiro; UC: Universidade de Coimbra; UÉ: Universidade de Évora; UL: Universidade de Lisboa; UTAD: Universidade de Trás-os-Montes e Alto Douro; UAlg: Universidade do Algarve; UMinho: Universidade do Minho; UPorto: Universidade do Porto; UAç: Universidade dos Açores; UNL: Universidade Nova de Lisboa.

\section{Referências}

Almeida Filho, N. (2016). A universidade brasileira num contexto globalizado de mercantilização do ensino superior: colleges vs. Vikings. Revista Lusófona de Educação, 32, 11-30.

Augé, M. (1994). Não-lugares: introdução a uma antropologia da supermodernidade. Campinas: Papirus.

Bardin, L. (2011). Análise de conteúdo. Lisboa, Portugal: Edições 70.

Broilo, C. L. (2015). Assessoria Pedagógica na Universidade: (con)formando o trabalho docente. Araraquara: Junqueira \& Marin.

Cunha, M. I. (Org.) (2010a). Trajetórias e Lugares de Formação da Docência Universitária: da perspectiva individual ao espaço institucional. Araraquara: Junqueira \& Marin; Brasília: Capes, CNPq.

Cunha, M. I. (2010b). Impasses contemporâneos para a Pedagogia Universitária no Brasil: implicações para os currículos e a prática pedagógica. In C. Leite (Org.). Sentidos da Pedagogia no Ensino Superior (pp. 63-74). Porto: CllE/Livpsic.

Cunha, M. I. (Org.) (2014). Estratégias institucionais para o desenvolvimento profissional docente e as assessorias pedagógicas universitárias: memórias, experiências, desafios e possibilidades. Araraquara: Junqueira \& Marin.

Gomes, S. \& Tavares, M. (2017). Formação continuada de professores da educação superior: novas linguagens, nova práticas, novos desafios. Revista Lusófona de Educação, 36, 25-39. 
Leite, C. (2002). A figura do "amigo crítico" no assessoramento / desenvolvimento de escolas curricularmente inteligentes. In M. Fernandes et. al.. O particular e o global no virar do milênio: cruzar saberes em educação (pp. 95-100). Porto: Sociedade Portuguesa de Ciências da Educação.

Leite, C. (Org.) (2010). Sentidos da Pedagogia no Ensino Superior. Porto: CllE/Livpsic.

Leite, C. \& Ramos, K. (2014). Políticas do Ensino Superior em Portugal na fase pós-Bolonha: implicações no desenvolvimento do currículo e das exigências ao exercício docente. Revista Lusófona de Educação, 27, 73-89.

Leite, C. \& Ramos, K. (2015). Reconfigurações da docência universitária: um olhar focado no Processo de Bolonha. Educar em Revista, 57, 33-47.

Lucarelli, E. (2007). Pedagogia universitária e inovação. In M. I. Cunha (Org.). Reflexões e práticas em pedagogia universitária (pp. 75-92). Campinas: Papirus.

Lucarelli, E. (2008). Asesoria pedagógica y cambio en la Universidad. Profesorado: revista de curriculum y formación del profesorado, 12(1), 1-14.

Xavier, A. R. C. (2014). Universidade Nova: desafios da prática pedagógica numa perspectiva interdisciplinar. Dissertação de Mestrado em Educação. Rio Claro: UNESP.

Xavier, A. R. C., Toti, M. C. S. \& Azevedo, M. A. R. (2017). Institucionalização da Formação Docente: análise de um programa de desenvolvimento profissional. Revista Brasileira de Estudos Pedagógicos, 249(98), 332-346.

Amanda Rezende Costa Xavier

Universidade Estadual Paulista Júlio de Mesquita Filho - Unesp Campus Rio Claro

Programa de Pós-Graduação em Educação / Universidade do Porto - Faculdade de Psicologia e de Ciências da Educação (FPCEUP)

Poços de Caldas, Minas Gerais, Brasi Email: arezendexavier@hotmail.com ORCID: 0000-0003-0097-3577

Carlinda Leite Universidade do Porto / Faculdade de Psicologia e de Ciências da Educação (FPCEUP) / Centro de Investigação e Intervenção Educativas (CIIE)

Porto, Portugal. Email: carlinda@fpce.up.pt ORCID:0000-0001-9960-2519

Data de submissão: Dezembro 2018

Data de avaliação: Março 2019 Data de publicação: Setembro 2019 